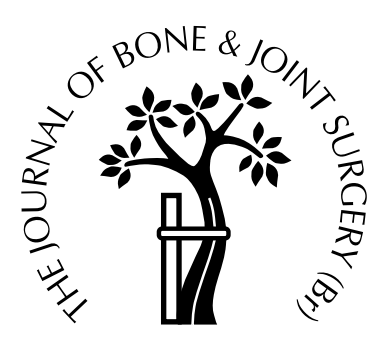

\title{
UNIPOLAR OR BIPOLAR PROSTHESIS FOR DISPLACED INTRACAPSULAR HIP FRACTURE IN OCTOGENARIANS
}

\author{
A RANDOMISED PROSPECTIVE STUDY \\ S. J. CALDER, G. H. ANDERSON, C. JAGGER, W. M. HARPER, P. J. GREGG \\ From Glenfield General Hospital, Leicester Royal Infirmary, and the University of Leicester, \\ England
}

We performed a randomised prospective trial to compare a cemented unipolar prosthesis (Thompson) with a cemented bipolar prosthesis (Monk) in the treatment of displaced intracapsular fractures of the hip in patients over 80 years of age. Patients with a mental test score of less than $5 / 13$ were excluded but the mortality was still about $30 \%$ at one year in both groups. We therefore feel that subjective criteria such as the level of pain and the return to the preinjury state are of paramount importance.

Two years after operation there was no statistical difference between the rate of complications in the two groups. After adjusting for confounding factors such as differences in the level of function before injury between the groups, the degree of return to the preinjury state was significantly greater $(p=0.04)$ when using the unipolar prosthesis, which is one-quarter of the price of the bipolar.

We cannot therefore justify the use of an expensive bipolar prosthesis in patients over 80 years of age.

J Bone Joint Surg [Br] 1996;78-B:391-4.

Received 12 June 1995; Accepted after revision 29 November 1995
S. J. Calder, FRCS, Research Fellow

W. M. Harper, MD, FRCS, Senior Lecturer

P. J. Gregg, MD, FRCS, Professor of Orthopaedic Surgery

University Department of Orthopaedic Surgery, Glenfield General Hospital, Groby Road, Leicester LE3 9QP, UK.

G. H. Anderson, FRCS Orth, Senior Registrar

Department of Orthopaedic Surgery, Leicester Royal Infirmary, Infirmary Square, Leicester LE1 5WW, UK.

C. Jagger, PhD, Senior Lecturer

Department of Epidemiology and Public Health, University of Leicester, 22-28 Princess Road West, Leicester LE1 6TP, UK.

Correspondence should be sent to Mr S. J. Calder at 12 Park Lane, Roundhay, Leeds LS8 2EU, UK.

(C)1996 British Editorial Society of Bone and Joint Surgery 0301-620X/96/31173\$2.00
Treatment of displaced intracapsular fracture of the hip by hemiarthroplasty in very old patients is generally satisfactory. D'Arcy and Devas (1976) found a rate of acetabular erosion of only $1.5 \%$ in those over 80 years of age compared with $16 \%$ in the 60-to-79-year age group after the use of a Thompson prosthesis.

Barnes et al (1976) reported a failure rate of almost 50\% for internal fixation in women over 84 years, but Skinner et al (1989) did not find age to be a factor. Two randomised prospective trials have found hemiarthroplasty to be better than internal fixation for patients over 67 (Søreide, Mölster and Raugstad 1979) and 70 years of age (Sikorski and Barrington 1981). Even in undisplaced fractures, the failure of fixation requiring a further operation has been reported in $31 \%$ of octogenarians, compared with $7 \%$ in those aged 65 to 79 years (Hui et al 1994). In the very elderly, however, hemiarthroplasty is generally accepted as the preferred treatment with less chance of a further operation.

The reduction of pain after hemiarthroplasty when the prosthesis has been cemented has been shown in retrospective reviews (Follacci and Charnley 1969; Gingras, Clarke and Evarts 1980) and in randomised studies of uncemented versus cemented procedures (Sonne-Holm, Walter and Jensen 1982; Emery et al 1991). Less pain and better residual function were found using a cemented Thompson compared with an uncemented Moore prosthesis (Wrighton and Woodyard 1971) and Yamagata et al (1987) found that cement fixation of the femoral component led to a higher rate of survival.

The choice between unipolar and bipolar prostheses is less clear. The main theoretical advantage of a bipolar over a unipolar prosthesis is the reduction of acetabular erosion due to movement taking place within the implant rather than between the head of the prosthesis and the acetabulum, although there is variation in the comparative distribution of the movement (Brueton et al 1993). Movement within the prosthesis may also reduce the pain caused by the prosthesis moving against the acetabulum. A randomised prospective study did not show any differences in Harris scores, loosening or acetabular erosion between the Moore unipolar and Bateman bipolar prosthesis at three years (van Thiel et al 1988), but other retrospective studies disagree with these findings. Yamagata et al (1987) found more erosion with unipolar prostheses and Wetherell and Hinves (1990) 
Table I. Clinical details and preoperative dependency and disability levels in the two groups of patients

\begin{tabular}{llll}
\hline & \multicolumn{2}{l}{ Prosthesis } & \\
\cline { 2 - 3 } & Monk $(\mathbf{n}=\mathbf{1 1 8})$ & Thompson $(\mathbf{n = 1 3 2})$ & p value \\
\hline Female $(\% ;$ number) & $85.6(101)$ & $86.4(114)$ & $0.86^{*}$ \\
Resident in the community $(\% ;$ number) & $84.7(100)$ & $78.8(104)$ & $0.27^{*}$ \\
Independent or one stick only (\%; number) & $72.0(85)$ & $73.5(97)$ & $0.43^{*}$ \\
Able to go out alone (\%; number) & $46.6(55)$ & $43.2(57)$ & $0.57^{*}$ \\
Independent of carers (\%; number) & $22.0(26)$ & $18.2(24)$ & $0.38^{*}$ \\
Median age (years; IQ range) & $85(82$ to 88$)$ & $85(82$ to 88$)$ & $0.82 \dagger$ \\
Median MTS score (IQ range) & $13(11$ to 13$)$ & $12(10$ to 13$)$ & $0.33 \dagger$ \\
\hline$*=$ chi-squared test & & & \\
$\dagger=$ Mann-Whitney U test & & &
\end{tabular}

reported a rate of erosion of $5.6 \%$ with the Hastings bipolar implant compared with $11 \%$ for the cemented Thompson prosthesis. Retrospective studies, however, may suggest better results with the bipolar prosthesis because the patients may have been selected for this procedure by virtue of their younger age.

The choice of outcome measures for very elderly patients is contentious, because their limited life expectancy makes their early satisfaction as important as more objective longer-term criteria. A bipolar prosthesis costs four times more than a unipolar prosthesis; this difference is significant, given the high incidence of these fractures.

\section{PATIENTS AND METHODS}

We studied 250 patients over 80 years of age with a displaced intracapsular fracture of the hip (Garden stage III to IV). Patients were excluded from the study if they had:

1) A mental test score (MTS) of less than 5/13. Dementia has been shown to predispose to a high mortality in these patients (Evans, Prudham and Wandless 1979; Wood et al 1992). We used an abbreviated MTS, scored out of 13 (Blessed, Tomlinson and Roth 1968).

2) Uncontrolled Parkinson's disease. This is associated with a high rate of dislocation after hemiarthroplasty (Coughlin and Templeton 1980; Staeheli, Frassica and Sim 1988).

3) Disseminated malignancy or pathological fracture.

4) Paget's disease involving the proximal femur on the side of the fracture.

5) Rheumatoid arthritis and long-term steroid therapy.

Patients were assigned either to a Thompson unipolar (Corin Medical Ltd, Cirencester, UK) or a Monk ('hardtop') bipolar (Johnson and Johnson Orthopaedics, Bracknell, UK) hemiarthroplasty by computerised random-number generation. There were 118 Monk and 132 Thompson prostheses. Each prosthesis had an identical curved stem and collar, and differed only in the articulating component which in the Thompson was solid and in the Monk was bipolar with a $25 \mathrm{~mm}$ intraprosthetic articulation.

Initial assessment of the patients was carried out by one surgeon. Details of their home circumstances, mobility, use of walking aids, general medical health, and previous fractures were recorded. All patients gave informed signed consent.

The operations were carried out by the same surgeon. The method of anaesthesia was recorded. A Hardinge direct lateral approach was used in the same conventional operating theatre which did not have laminar flow air supply. The prostheses were cemented into the femur with normal viscosity cement in an orthograde manner using a syringe and a vent but no cement restriction.

Postoperatively, all patients were mobilised fully weightbearing after 24 to 48 hours with assistance from physiotherapists. They were reviewed regularly during their stay in hospital; all complications were noted. Outpatient assessment was carried out by one surgeon at six to eight weeks after operation. The wound was checked and a plain standing anteroposterior pelvic radiograph was taken. Subsequently, patients were reviewed annually. Further radiographs and a series of subjective assessments were made including comparison with the state of the hip before injury, the presence of a limp, pain, satisfaction with the operation and the Harris hip score.

\section{RESULTS}

Differences between the groups as regards age, gender, preinjury residence (community/institutional care), preoperative levels of social dependency (carer/self care) and the use of walking aids were not statistically significant at the 5\% level (Table I). The length of stay in hospital was not significantly different for the two groups (Mann-Whitney U test, $\mathrm{p}=0.40$ ); patients with the Monk prosthesis spent a median of 17 days in hospital (13 to 22) while those with a Thompson prosthesis had a median hospital stay of 18 days (13 to 23). Slightly fewer of the Monk group died while in hospital; 7 (5.9\%) compared with 14 (10.6\%) of the Thompson group (chi-squared test $=1.65, \mathrm{df}=2, \mathrm{p}=0.20$ ). Of the Monk group, $48(40.7 \%)$ returned to their preoperative place of residence compared with 56 (42.4\%) of the Thompson group (chi-squared test $=0.02, \mathrm{df}=1, \mathrm{p}=0.88$ ). We found no significant difference in survival time between the 
Table II. Proportionate survival (percentage) in the two groups

\begin{tabular}{lll}
\hline \multirow{2}{*}{ Months } & Prosthesis & \\
\cline { 2 - 3 } & Monk $(\mathbf{n}=\mathbf{1 1 8})$ & Thompson $(\mathbf{n}=\mathbf{1 3 2})$ \\
\hline 0 & 100 & 100 \\
2 & 85 & 83 \\
4 & 81 & 79 \\
6 & 78 & 75 \\
8 & 73 & 74 \\
10 & 71 & 71 \\
12 & 69 & 72 \\
\hline
\end{tabular}

two groups at one year from operation (log-rank test, $\mathrm{p}=$ 0.79). Table II shows the proportion surviving to various times from the date of operation. At two years 141 patients were reviewed, 67 of the Monk group and 74 of the Thompson group. Assessment was usually undertaken at an outpatient clinic but a small number were contacted by telephone (7) or seen at home (1). The median time of follow-up for the Monk group was slightly longer than for the Thompson (Table III). Analysis of the data was on an 'intention-totreat' basis (Table III). The outcomes of return to the prein-

Table III. Follow-up assessments of the two groups. Calculations use all randomised patients on an 'intention-to-treat' basis and include loss to follow-up by death or otherwise, but are before corrections for confounding factors (see text)

\begin{tabular}{|c|c|c|c|}
\hline & \multicolumn{2}{|l|}{ Prosthesis } & \multirow[b]{2}{*}{ p value } \\
\hline & Monk $(n=118)$ & Thompson $(n=132)$ & \\
\hline $\begin{array}{l}\text { Returned to preinjury } \\
\text { state-subjective (\%; number) }\end{array}$ & $39.8(47)$ & $28.8(38)$ & $0.07 *$ \\
\hline No limp-subjective (\%; number) & $21.2(25)$ & $17.4(23)$ & $0.45^{*}$ \\
\hline No or mild pain (\%; number) & $55.1(65)$ & $53.0(70)$ & $0.75^{*}$ \\
\hline $\begin{array}{l}\text { Satisfied with operation (\%; } \\
\text { number) }\end{array}$ & $53.4(63)$ & $50.8(67)$ & $0.68 *$ \\
\hline $\begin{array}{l}\text { Median follow-up time } \\
\text { in days (IQ range) } \dagger\end{array}$ & 694 (390 to 864) & 594 (380 to 790$)$ & $0.58 \div$ \\
\hline Median Harris score (IQ range) & $72.0(67.0$ to 79.0$)$ & $70.0(65.0$ to 77.0$)$ & $0.23 \ddagger$ \\
\hline $\begin{array}{l}* \text { chi-squared test } \\
\dagger \text { survivors only } \\
\ddagger \text { Mann-Whitney U test }\end{array}$ & & & \\
\hline
\end{tabular}

jury state, limp, pain and satisfaction with the operation were classed as yes or no; patients dying before follow-up or not contactable were included in the 'no' group. Using this method of analysis, the Monk group appeared to enjoy higher levels of function although the differences were not statistically significant (Table III). The Harris scores of the groups did not differ significantly. To determine whether differences in the results were masked by the variation in follow-up time and in function before injury (Table I) we performed logistic regression to adjust for these potential confounding factors. For those who had died, follow-up was calculated as the survival time from operation, while for those alive but lost to follow-up the length of stay in hospital was used. Other potential confounding factors included in the statistical models were differences in age at operation, gender, preinjury residence, MTS, and independence of walking before injury.

After adjustment for these factors there were still no significant differences between the two groups for pain, limp, satisfaction or Harris score. There was, however, a significantly greater return to the preinjury state for the Thompson group (Wald chi-squared test $=4.18, \mathrm{df}=1, \mathrm{p}=0.041$ ), with odds of 1.94 (95\% confidence interval 1.03 to 3.67 ) compared with the Monk group.

There were no significant differences in the rate of deep infection (Monk 4/118, Thompson 5/132), dislocation (1/
$118,2 / 132)$, or gross radiological acetabular erosion $(0 / 118$, 3/132), using chi-squared analysis.

\section{DISCUSSION}

The mortality after one year was $30 \%$ even after the exclusion of patients with high-risk factors such as dementia. The early subjective outcomes in elderly patients are of paramount importance, particularly in view of the high mortality; the optimum realistic outcome should be to return to the levels of function before injury. Subjective measures of outcome may be more important than conventional assessments such as the Harris score, which is, however, largely based on pain and functional ability and the radiological findings.

Acetabular erosion after hip hemiarthroplasty is a longerterm problem in younger patients. There were three cases in the unipolar group and none in the bipolar, which may demonstrate the theoretical benefit of the bipolar prosthesis, although the differences were not statistically significant. The radiographs of these patients showed protrusio but operative revision was not required.

The review at follow-up was not blind and this should be noted when assessing the results, although efforts were made to avoid bias by asking the relevant questions and undertaking clinical examination before the radiographs were inspected. 
When planning the study the power was calculated from an assumed rate of reoperation of 5\% at five years; this would require over $80 \%$ power to detect as significant (at the $5 \%$ level) a difference of $15 \%$, and over $95 \%$ power to detect a difference of $20 \%$ between the two groups. The current death rate of around 30\% in the year after operation is, however, higher than was assumed from the first year of the trial and considerably greater than the annual death rate of $12 \%$ for this age group nationally (Office of Population Censuses and Surveys 1989).

Our results suggest that a unipolar prosthesis may give better short-term results in octogenarians. Whether this is sustained in the long term or offset by a higher rate of revision will become clear in the future. It may be that younger patients who are more mobile would benefit more from a bipolar implant. We have studied its use in a younger age group (65 to 79 years), but longer follow-up is needed to assess the results. We see no justification for the use of the expensive bipolar hip prosthesis in patients over 80 years of age, regardless of their mental state or mobility.

No benefits in any form have been received or will be received from a commercial party related directly or indirectly to the subject of this article.

\section{References}

Barnes R, Brown JT, Garden RS, Nicoll EA. Subcapital fracture of the femur: a prospective review. J Bone Joint Surg [Br] 1976;58-B:2-24.

Blessed G, Tomlinson BE, Roth M. The association between quantitative measures of dementia and of senile change in the cerebral grey matter of elderly subjects. Brit J Psychiat 1968;114:797-811.

Brueton RN, Craig JS, Hinves BL, Heatley FW. Effect of femoral component head size on movement of the two component hemiarthroplasty. Injury 1993;24:231-5.

Coughlin L, Templeton J. Hip fractures in patients with Parkinson's disease. Clin Orthop 1980;148:192-5.

D'Arcy J, Devas M. Treatment of fractures of the femoral neck by replacement with the Thompson prosthesis. J Bone Joint Surg [Br] 1976;58B:279-86.
Emery RJH, Broughton NS, Desai K, Bulstrode CJK, Thomas TL. Bipolar hemiarthroplasty for subcapital fracture of the femoral neck: a prospective randomised trial of cemented Thompson and uncemented Moore stems. J Bone Joint Surg [Br] 1991;73-B:322-4.

Evans JG, Prudham D, Wandless I. A prospective study of fractured proximal femur: factors predisposing to survival. Age Ageing 1979;8:246-50.

Follacci FM, Charnley J. A comparison of the results of femoral head prosthesis with and without cement. Clin Orthop 1969;62:156-61.

Gingras MB, Clarke J, Evarts CM. Prosthetic replacement in femoral neck fractures. Clin Orthop 1980;152:147-57.

Hui ACW, Anderson GH, Choudhry R, Boyle J, Gregg PJ. Internal fixation or hemiarthroplasty for undisplaced fractures of the femoral neck in octogenarians. J Bone Joint Surg [Br] 1994;76-B:891-4.

Office of Population Censuses and Surveys. Mortality statistics, England and Wales. London: HMSO, 1989;DH1:No. 20.

Sikorski JM, Barrington R. Internal fixation versus hemiarthroplasty for the displaced subcapital fracture of the femur: a prospective study. $J$ Bone Joint Surg [Br] 1981;63-B:357-61.

Skinner P, Riley D, Ellery J, et al. Displaced subcapital fractures of the femur: a prospective randomised comparison of internal fixation, hemiarthroplasty and total hip replacement. Injury 1989;20:291-3.

Sonne-Holm S, Walter S, Jensen JS. Moore hemi-arthroplasty with and without bone cement in femoral neck fractures: a clinical controlled trial. Acta Orthop Scand 1982;53:953-6.

Søreide O, Mölster A, Raugstad TS. Internal fixation versus primary prosthetic replacement in acute femoral neck fractures: a prospective, randomized clinical study. Br J Surg 1979;66:56-60.

Staeheli JW, Frassica FJ, Sim FH. Prosthetic replacement of the femoral head for fracture of the femoral neck in patients who have Parkinson disease. J Bone Joint Surg [Am] 1988;70-A:565-8.

van Thiel PH, Snellen JP, Jansen WBJ, van de Slikke W. Moore prosthesis versus bipolar Bateman prosthesis: a prospective randomised clinical study. J Bone Joint Surg [Br] 1988;70-B:677.

Wetherell RG, Hinves BL. The Hastings bipolar hemiarthroplasty for subcapital fractures of the femoral neck: a 10-year prospective study. J Bone Joint Surg [Br] 1990;72-B:788-93.

Wood DJ, Ions GK, Quinby JM, Gale DW, Stevens J. Factors which influence mortality after subcapital hip fracture. J Bone Joint Surg $[\mathrm{Br}]$ 1992;74-B:199-202.

Wrighton JD, Woodyard JE. Prosthetic replacement for subcapital fractures of the femur: a comparative survey. Injury 1971;2:287-93.

Yamagata M, Chao EY, Ilstrup DM, et al. Fixed-head and bipolar hip endoprostheses: a retrospective clinical and roentgenographic study. $J$ Arthroplasty 1987;2:327-41. 